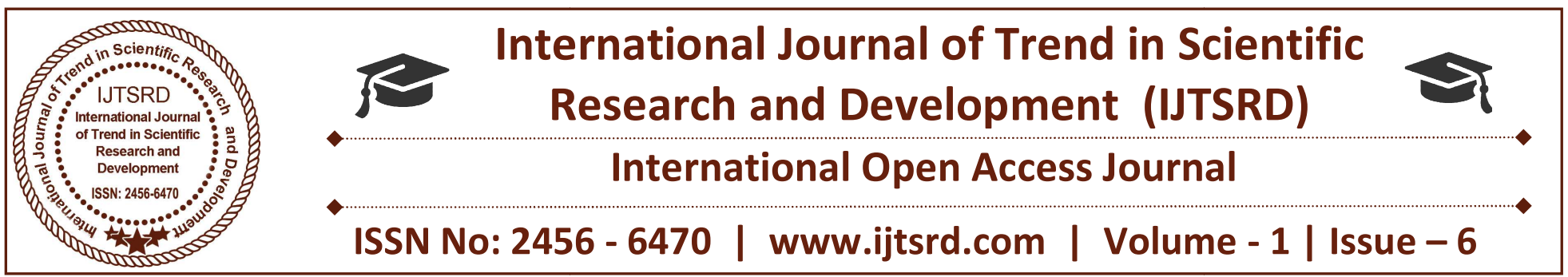

\title{
A Study on Neikuri in Hypertension
}

\author{
S. Mohamed Ajmal \\ UG Scholar, Sivaraj Siddha \\ Medical College, Salem, \\ Tamilnadu, India
}

\author{
M. Nagalakshmi \\ UG Scholar, Sivaraj Siddha \\ Medical College, Salem, \\ Tamilnadu, India
}

\author{
A. Raja Rajeswari \\ Lecturer, Department of Noi \\ Naadal, Sivaraj Siddha Medical \\ College, Salem, Tamilnadu, India
}

\section{ABSTRACT}

The methodology of diagnosis in Siddha system is based on eight fold examinations of pulse, reflex, tongue, body color and complexion, speech, eyes and sight, stools and urine. Of all these parameters, Urine examination has gained paramount importance next to pulse examination. Neikuri is a diagnostic tool of urine examination using Sesame seed oil developed by Siddhars and also throws a light on prognosis of disease condition. This is an attempt to understand the Siddha system of diagnosing pathological conditions which are a non-invasive, highly cost effective procedure which can be used for both diagnostic and prognostic purposes. This study aims to validate the Neikuri image on the patients diagnosed as Hypertension. For the purpose of the study, ten urine samples of Hypertension patients were collected and the oil drop test was conducted using the guidelines mentioned the Siddha Literature. Majority of samples showed a ring shape like circle under Iyam humor. This study can be used as referenced diagnostic criteria for Hypertension.

\section{INTRODUCTION}

Siddha system of medicine is a traditional medical system has been practiced in India for 2000 years. Vali, Azhal, Iyam are the three humors and their equilibrium disturbances produces pathological states.[1] The diagnosis in siddha system of medicine is based on eight fold examination methods like, (Naadi, Naa, Niram, Mozhi, Vizhi, Sparism, Malam, Moothiram (Neerkuri and Neikuri). Of these Neikuri(oil drop test) is important[2]. It is used for diagnosis and prognostic purposes. Neikuri is done in patient urine is collected in a vessel, a drop of sesame oil is placed over and spreading of oil drop on the urine surface is noted[3]. The present study was planned to validate the Siddha diagnostic procedure (Neikuri) in Hypertension. The study was carried out to validate the Neikuri for Hypertension.

\section{Materials and Methods}

\section{Neikuri}

Sterile plastic container for urine collection, round glass bowl, toothpick, urine of patients, sesameseed oil.

\section{Selection of patients}

Total number of 10 patients of Hypertension were taken for this study. For this study 25 patients were screened from the out patients of Sivaraj Siddha Medical College, Salem, Tamilnadu.

\section{Criteria for inclusion}

Age 20 to 60, patients having only Hypertension were consider for selection.

\section{Collection of urine sample}

The methodology for the collection of urine sample from the patients mentioned in the literature was strictly followed. On the day before, selected patients were advised to eat six tastes of food and were asked to sleep well. On the next day early morning they were asked to collect the urine sample in the provided $100 \mathrm{ml}$ container [4].

\section{Urine examination with oil drop}

A $50 \mathrm{ml}$ of urine is collected in a sterile plastic container and transformed in to a round glass bowl and kept on a flat surface without disturbing. A drop 
International Journal of Trend in Scientific Research and Development (IJTSRD) ISSN: 2456-6470

of sesame oil was dropped at the center over the surface. The pattern of oil spread was keenly observe surface of urine in a round glass bowl by using a under sunlight at 0, 30,60 seconds. The observations toothpick at a distance of $6 \mathrm{~cm}$ height from the urine are noted diagrammatically and inference is noted.

\begin{tabular}{|c|c|c|c|c|c|c|c|}
\hline \multirow[t]{2}{*}{ S.NO } & \multirow{2}{*}{$\begin{array}{l}\text { Blood } \\
\text { pressure } \\
\text { (mmHg) }\end{array}$} & \multicolumn{4}{|c|}{ Image of oil spread over the surface } & \multirow{2}{*}{$\begin{array}{l}\text { Pattern of } \\
\text { oil } \\
\text { Spread }\end{array}$} & \multirow{2}{*}{$\begin{array}{l}\text { Inferences releated with } \\
\text { Humours }\end{array}$} \\
\hline & & 0 second & \begin{tabular}{|l|}
15 \\
seconds
\end{tabular} & $\begin{array}{l}30 \\
\text { seconds }\end{array}$ & $\begin{array}{l}60 \\
\text { seconds }\end{array}$ & & \\
\hline $\mathbf{1}$ & $150 / 110$ & & & & & Kabham & $\begin{array}{l}\text { On the surface of urine oil } \\
\text { drop } \\
\text { stays as pearl }\end{array}$ \\
\hline 2 & $150 / 110$ & & & & & Kabham & $\begin{array}{l}\text { On the surface of urine oil } \\
\text { drop } \\
\text { stays as pearl }\end{array}$ \\
\hline 3 & $140 / 110$ & & & & & Kabham & $\begin{array}{l}\text { On the surface of urine oil } \\
\text { drop } \\
\text { stays as pearl }\end{array}$ \\
\hline 4 & $150 / 110$ & & & & & Kabham & $\begin{array}{l}\text { On the surface of urine oil } \\
\text { drop } \\
\text { stays as pearl }\end{array}$ \\
\hline 5 & $150 / 110$ & & & & & Kabham & $\begin{array}{l}\text { On the surface of urine oil } \\
\text { drop } \\
\text { stays as pearl }\end{array}$ \\
\hline 6 & $160 / 120$ & & & & & Kabham & $\begin{array}{l}\text { On the surface of urine oil } \\
\text { drop } \\
\text { stays as pearl }\end{array}$ \\
\hline 7 & $170 / 120$ & & & & & $\begin{array}{l}\text { Pitha } \\
\text { vaatham }\end{array}$ & $\begin{array}{l}\text { On the surface of urine the } \\
\text { oil } \\
\text { spread slowly and form a } \\
\text { ring } \\
\text { shape and beak appearance. }\end{array}$ \\
\hline 8 & $170 / 120$ & & & & & $\begin{array}{l}\text { Pitha } \\
\text { vaatham }\end{array}$ & $\begin{array}{l}\text { On the surface of oil drop } \\
\text { spread } \\
\text { medium like a ring elongated } \\
\text { as } \\
\text { irregular pattern. }\end{array}$ \\
\hline 9 & $160 / 120$ & & & & & Pitham & $\begin{array}{l}\text { On the surface of oil drop } \\
\text { spread } \\
\text { medium like a ring as } \\
\text { irregular pattern. }\end{array}$ \\
\hline 10 & $150 / 100$ & & & & & Kabham & $\begin{array}{l}\text { On the surface of urine oil } \\
\text { drop } \\
\text { stays as pearl, }\end{array}$ \\
\hline
\end{tabular}




\section{Results and Discussion}

In traditional system of medicine Neikuri an oil drop test in urine is a cost effective diagnostic procedure carried out to rule out the diseased condition. By the mode of spread of oil in the urine, diagnoses are made. Neikuri is based on the consistency, thickness, density of urine and the interfacial tension and viscous forces play a major role. The procedure of spreading pattern of oil on urine and the interpretation of the outcomes are clearly mentioned by Theraiyar in the literature of Siddha and it is discussed below. If the oil drop takes the shape of a snake, it indicates the body is Vali humors. If it spreads like a ring it indicates Azhal and if it stands like a pearl it indicates Iyam humours. These spread patterns indicates normal physiological state. If there is a combined shape like a ring in a snake or snake in ring, snake and a pearl or a pearl in the ring. The results of table 1 show that among ten patients diagnosed as Hypertension, majority of Neikuri $80 \%$ interpreted the image of Pearl. The Pearl shaped pattern of the oil drop indicates the patients were predominantly under Iyam humor. This signs indicates that the patients were not in normal physiological state.

\section{Conclusion}

From the above results, it is concluded that the oil drop stands like a pearl and produce the image of Pearl shape might be one of the diagnostic feature of the Hypertension disease. The present study was a preliminary to ascertain the mode of oil spread in urine of Hypertension patients. In future, large number of samples will be studied to standardize this oil drop test in various diseased patients.

\section{References}

1. Uthamarayan C.S. Siddha MaruthuvangaChurukkam. 2nded. Chennai:Department of Indian Medicine and Homoeopathy; 2006.

2. Shanmugavelu M. NoinaadalnoimudhalnaadalThiratu. Part I. Chennai: Department of Indian Medicine and Homeopathy; 2003. p. 269.

3. Shanmugavelu M. NoinaadalnoimudhalnaadalThiratu. Part I. Chennai: Department of Indian Medicine and Homeopathy; 2003. p. 282.

4. Ramachandran

Therayarneerkurivaithiyam, neerkurinool neikurinool, moolamumuraiyum. 2nd ed Chennai: Thamarainoolagam 